\title{
Morphometric analysis of body and claw dimensions of building dwelling UK bat species: to aid knowledge of bat interactions with roosting surfaces
}

Article

Accepted Version

Waring, S. D. and Essah, E. A. (2016) Morphometric analysis of body and claw dimensions of building dwelling UK bat species: to aid knowledge of bat interactions with roosting surfaces. Acta Chiropterologica, 18 (2). pp. 527-534. ISSN 1508-1109 doi:

https://doi.org/10.3161/15081109ACC2016.18.2.019 Available at https://centaur.reading.ac.uk/68377/

It is advisable to refer to the publisher's version if you intend to cite from the work. See Guidance on citing.

Published version at: http://www.bioone.org/page/about/organization/mission

To link to this article DOI: http://dx.doi.org/10.3161/15081109ACC2016.18.2.019

Publisher: Museum and Institute of Zoology, Polish Academy of Sciences

All outputs in CentAUR are protected by Intellectual Property Rights law, including copyright law. Copyright and IPR is retained by the creators or other copyright holders. Terms and conditions for use of this material are defined in the End User Agreement. 


\section{www.reading.ac.uk/centaur}

\section{CentAUR}

Central Archive at the University of Reading

Reading's research outputs online 


\title{
Morphometric analysis of body and claw dimensions of building dwelling UK bat species: To aid knowledge of bat interactions with roosting surfaces
}

\author{
StACEy. D. WARING ${ }^{1}$, EMmAnUEl. A. EsSAH ${ }^{2}$ \\ ${ }^{1}$ Technologies for the Sustainable Built Environment Centre, School of the Built Environment, University of \\ Reading, Reading, RG6 6AF \\ ${ }^{2}$ School of the Built Environment, University of Reading, Reading, RG6 6AF
}

\begin{abstract}
The increasing use of non-woven materials, such as breathable roofing membranes (BRMs) within buildings that either currently contain a bat roost or may do in the future, has led to concerns over bat safety by those involved in bat conservation in the UK. Whilst some information is currently available on the selection of roosts in roofs by bats, along with technical specifications of individual membranes, there is no research that has investigated the interactions between the two. Prior to determining the methods needed to test interactions between bats and BRMs, a series of preliminary investigations were conducted; including research and physical measurements on selected anatomical features of bats commonly found roosting in buildings in the UK. Data on body size and shape were gathered from a combination of experimental measurements of bat specimens (deceased) and information collated from literature. Data on bat claw morphology were collected by applying a method used to measure raptor talons, measurements obtained included; width, length and the curvature (hook ratio) of their claws. The results of this research provide additional information about bat body and claw morphometrics. It was found that bat species/group had a significant effect upon the length, width and curvature of the claws (to varying degrees). Pipistrelle species have the shortest and third narrowest claws, whereas serotines have the longest and widest claws on average. The curvature of the claws does not vary greatly between species; however, more variation was seen in the lower portion of the claws. The results from this research also demonstrate that the current standard industry tests do not represent the fine scale at which a bats claws interact with their roosting surfaces. Consequently, this information can be used to aid the development of industry tests for determining the suitability of BRMs for use in bat roosts.
\end{abstract}

Key words: bats, claws, length, curvature, morphometrics, roosting surfaces 


\section{INTRODUCTION}

In the past fifteen years the use of non-woven textiles within the roofing industry has seen a significant rise (Masseneux, 2003), mainly through the production of Breathable Roofing Membranes (BRMs). Prior to this bituminous felt, as described in British Standard BS747:2000 (BSI, 2000a), was the main roofing underlay specified to be used within most roof spaces. Many buildings suitable for use as bat roosts often require re-roofing as they age. During re-roofing, traditional bituminous roofing felts are often replaced with BRMs, which are designed to facilitate the removal of water vapour from the roof in order to reduce the risk of condensation formation (Jansenns and Henns, 2003; Essah et al., 2009). In the UK alone there are currently over 60 brands of BRMs available as replacements to bituminous felt when roof spaces are being refurbished (Waring et al., 2013; Waring, 2014). This is one example of new materials being introduced into the building industry, often in an effort to meet sustainability targets (Waring, 2014).

BRMs are non-woven materials manufactured from spun-bonded polypropylene or spunbonded polypropylene/polyethylene filaments, laminated either side of a vapour permeable (functional) layer (Albrect, 2003). A nonwoven material can be defined as 'a manufactured sheet, web or batt of directionally or randomly orientated fibres, bonded by friction, and/or cohesion and/or adhesion' (Massenaux, 2003).

In order to ensure the spun-bond polypropylene filaments are strong enough to protect the functional layer during the fitting process, the industry carries out quality tests on its membranes. At present, in order to test the mechanical strength of BRMs, they are tested to conform to British Standard BS EN 863:1996 nail puncture resistance (BSI, 1996) and BS EN 12310-1:2000 determination of resistance to tearing tests (BSI, 2000b). This current level of industrial testing that is applied to BRMs is designed to consider the processes encountered in a roof when subjected to expected installation and service stresses and strains.

Consequently, products are designed to withstand these processes but not those that are unexpected, such as use by bats.

In order to pass these tests the BRMs must have properties that increase material strength, including long filaments and strong bonds between them (Witteveen and Lucas, 2000). The non-woven nature of these membranes means that strong filaments are often teased from the surface when a bat's claws interact with the surface (Waring, 2014). Consequently, the increasing use of BRMs within buildings that either currently contain a bat roost or may do in 
the future, has led to conservation concerns for bats safety (Morris, 2008; Schofield, 2008; Waring et al., 2013; Waring, 2014). These concerns have recently been substantiated with at least 290 reported bat deaths following entanglement in non-woven roofing membranes (Waring, 2014). This occurs where the spun-bond filaments used in the manufacture of these products have been teased free from the membrane surface due to bat claws snagging the surface of the products.

Whilst some information is currently available on the selection of roosts in roofs, biological flight adaptations (Yalden and Morris, 1975), crawling actions of bats (Neuweiler, 2000) and technical specifications of BRMs, there is no research that has considered the interactions between the two. As the first stage of work prior to investigating interactions between bats and BRMs, a series of preliminary investigations were completed. This included a review of existing information and physical measurements on selected anatomical features of bats. The focus of this work was to investigate body-size and shape and the morphology of bat claws to inform the development of experimental methods that could mimic the effects of UK bat species (from the families Vespertilionidae and Rhinolophidae) roosting upon a surface. These data were gathered from a combination of experimental measurements of bat specimens (deceased) and information collated from literature. The latter was used to supplement direct data collected, for species where suitable specimens were not available. The aim of this research was to provide knowledge of bat body and claw morphometrics so that current testing methods representation of the fine scale at which bat claws interact with the membranes surface, could be appraised.

\section{MAterials AND Methods}

Information on body mass, forearm length, thumb length, tibia length and body length was collected for the UK bat species commonly found roosting in buildings: common pipistrelle (Pipistrellus pipistrellus), soprano pipistrelle (Pipistrellus pygmaeus), brown long-eared bat (Plecotus auritus), grey long-eared bat (Plecotus austriacus), serotine (Eptesicus serotinus), lesser and greater horseshoe bats (Rhinolophus hipposideros and Rhinolophus ferrumequinum), whiskered bat (Myotis mystacinus), Brandt's bat (Myotis brandtii) and Natterer's bat (Myotis nattereri). In total 350 bat specimens were measured from the Natural History Museum (London) collection and deceased animals collected by Colin Morris from the Vincent Wildlife Trust. 
Of the 85 specimens measured of pipistrelle species, the majority (88\%) were labelled (identified and catalogued) prior to the re-classification of common and soprano pipistrelles (Barlow et al., 1997; Barlow and Jones, 1999). As a result, all data for pipistrelle bats were grouped together to prevent misidentification and ensure uniform analyses. Data from the two long-eared species were also grouped; although thumb length can be used as a distinguishing feature between these species, the difficulties in identification between the two species which have extremely similar characteristics (Racey, 2008) and the age of some specimens, meant that accurate classification to species level could not be determined. Finally whiskered and Brandt's bats were also grouped in this study, due to their similar morphological characteristics.

\section{Body Measurements}

Measurements of forearm length, thumb length and tibia length were taken, from preserved specimens of bats using digital callipers with an accuracy of $0.05 \mathrm{~mm}$, in accordance with the methods described by Dietz et al (2009). As these measurements were of bones, they were unaffected by the preserved state of the specimens. Values that were affected by the desiccation process following death, such as body weight and length, were obtained from peer-reviewed published literature and standard reference guides. As the range of forearm lengths is also well documented this information was also compiled from literature to validate measurements taken.

\section{Claw Measurements}

Data on bat claw morphology were collected using a method used to measure raptor talons, described by Fowler et al. (2009). This involved the recording of length and angle measurements of claws from preserved specimens. Measurements were obtained by taking high quality ( $\geq 10$ megapixels with a $12 x$ optical zoom and macro setting enabled) lateral view photographs of the bat thumb and foot claws. Each photo was taken against a reference scale to allow for use in AutoCAD 2011(Fig. 1). 

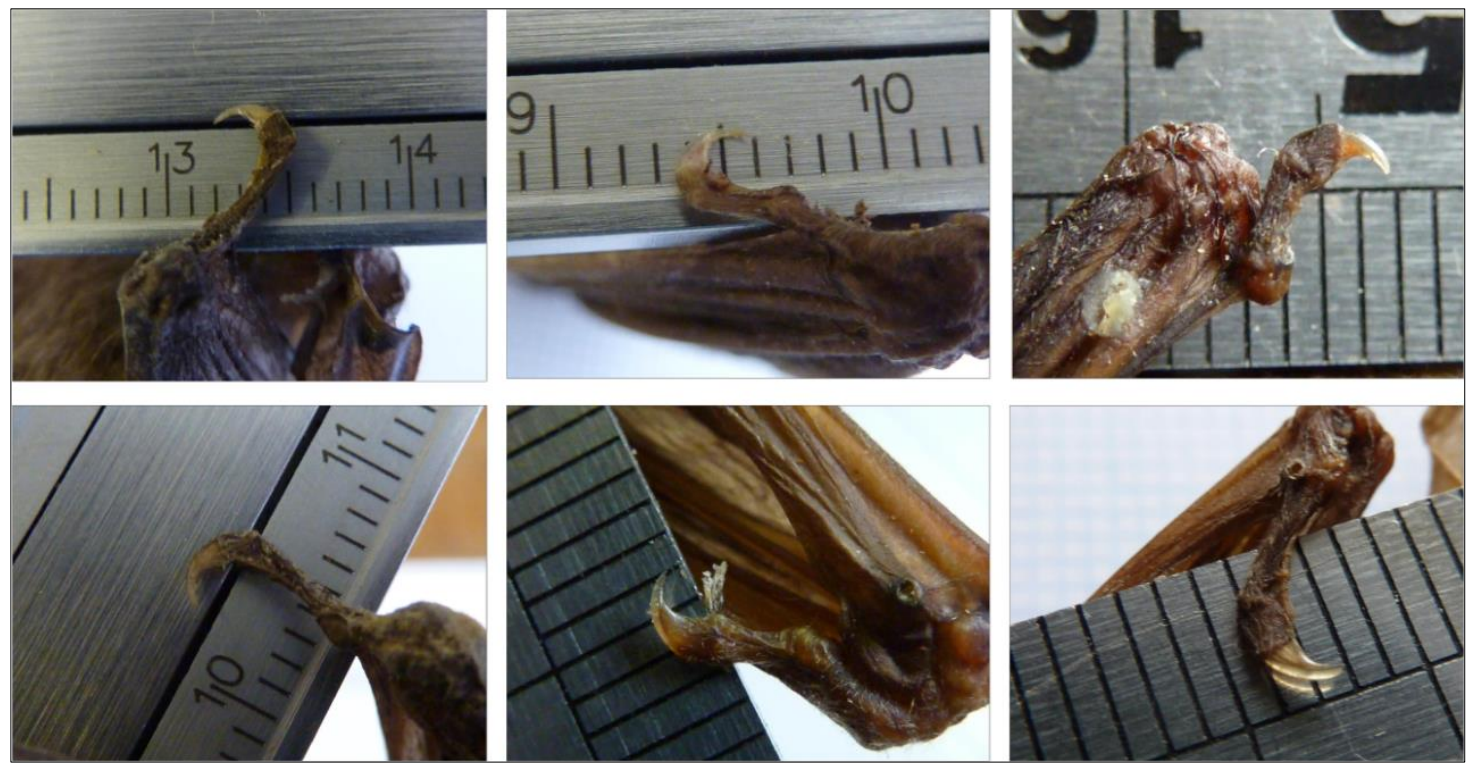

Fig. 1. Close up photos were taken of the thumb claw using a macro function. $1 \mathrm{~mm}$ scale bars can be seen in the image backgrounds.

The images were then imported as a picture image and embedded into AutoCAD 2011 software. Using AutoCAD tools available (polyline with dynamic input), the scale length was measured which allowed the dimensions of the claws to be calculated. The measurements recorded included; claw length (A), claw width (B), arc length $\left(\mathrm{AL}_{0}\right.$ for outer and $\mathrm{AL}_{\mathrm{i}}$ for inner), chord length ( $\mathrm{CL}_{o}$ for outer $\mathrm{CL}_{\mathrm{i}}$ for inner) and inner and outer curvature radii (Fig. 2).

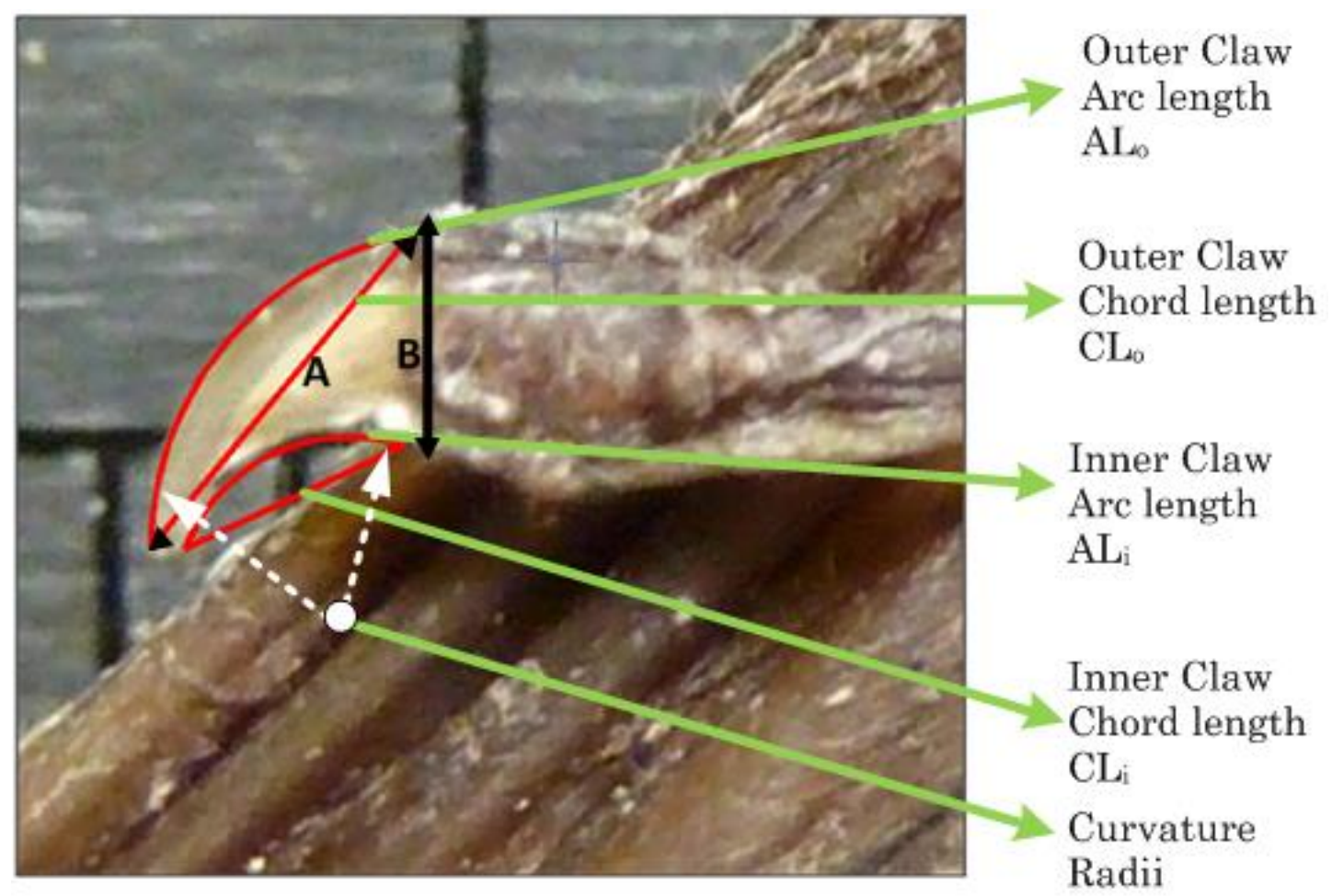

Fig.2. Visual description of the measurements obtained from bat claws in AutoCAD 2011 
For these measurements to be accurately recorded the images had to show a clear lateral view of the claw, resting against the $1 \mathrm{~mm}$ scale. Any images where the claw was not resting flat against the scale were discarded as measurements obtained in the AutoCAD software would be inaccurate and could distort the data. From 350 bat specimens available (across all species measured), 269 were of sufficient sampling quality to provide clear lateral images of the thumb claws, however, only 26 were in a condition that allowed lateral images of the foot claws. This was due to the fact that the majority of feet viewed were closed preventing a clear image of the claws being obtained.

The inner and outer hook ratios were calculated from the measurements taken from the images of bat claws, using Equation 1. These hook ratios allowed comparison of claw shape between species/species groups using statistical analyses.

$$
\text { Claw Hook Ratio }=\frac{A L_{o}}{C L_{o}} \text { or } \frac{A L_{i}}{C L_{i}}
$$

(Equation 1)

Statistical exploration showed that the data had a non-normal distribution and transformation attempts using $\log _{10}$ and SQRT did not normalise the data. Consequently, a parametric test such as one-way ANOVA could not be used as the assumption that the data were normally distributed was not met. Instead the comparison of means was achieved using a KruskalWallis non-parametric test and post-hoc Mann Whitney-U tests. In order to reduce Type I error, due to multiple comparisons on a single dataset, the Bonferroni Correction was applied. As a result the $\mathrm{p}$-value needed for the difference in claw width deemed significant was $\mathrm{p}<$ 0.00238. This correction was also applied to the post-hoc tests conducted on claw length, outer hook ratio and inner hook ratio.

These statistical analyses were applied to each of the four characteristics considered; claw width, claw length, outer hook ratio and inner hook ratio to determine if there were significant inter- species/group differences.

\section{Real World Comparison}

As the focus of this preliminary investigation was to inform the development of experimental methods that could mimic the effects of roosting bats; the measurements of claw width were compared to industry standard roofing nails as described in the two tests (BS EN 863:1996 and BS EN 12310-1:2000) BRMs are currently subjected to. This comparison was performed to exhibit how the mechanical properties of bat claws and roofing nails differ and how 
current testing methods applied to roofing underlays, are unsuitable for determining the effects of exposure to bat claws.

\section{RESUlTS}

\section{Body Measurements}

Table 1. Morphometrics for species of bat regularly found in buildings

\begin{tabular}{|c|c|c|c|c|c|c|c|}
\hline \multirow[b]{2}{*}{ Bat Species/group } & \multicolumn{4}{|c|}{ Data from Literature* } & \multicolumn{3}{|c|}{$\begin{array}{l}\text { Data from Specimen } \\
\text { Measurements }\end{array}$} \\
\hline & $\begin{array}{l}\text { Body } \\
\text { Mass } \\
\text { Range } \\
\text { (g) }\end{array}$ & $\begin{array}{l}\text { Head } \\
\text { and } \\
\text { Body } \\
\text { Length } \\
(\mathrm{mm})\end{array}$ & $\begin{array}{l}\text { Forear } \\
\mathrm{m} \\
\text { Length } \\
\text { Range } \\
(\mathrm{mm})\end{array}$ & $\begin{array}{l}\text { Thumb } \\
\text { Length } \\
\text { Range } \\
(\mathrm{mm})\end{array}$ & $\begin{array}{l}\text { Mean } \\
\text { Forearm } \\
\text { length } \\
(\mathrm{mm})\end{array}$ & $\begin{array}{l}\text { Mean } \\
\text { Thumb } \\
\text { Length } \\
(\mathrm{mm})\end{array}$ & $\begin{array}{l}\text { Mean } \\
\text { Tibia } \\
\text { Length } \\
(\mathrm{mm})\end{array}$ \\
\hline Pipistrelle sp. & $3-8$ & $35-45$ & $29-35$ & $* *$ & 30.6 & 3.9 & 11.6 \\
\hline Long-eared sp. & $6-12$ & $37-58$ & $34-45$ & $\begin{array}{l}5.2-6.6 \\
* * *\end{array}$ & 38.0 & 6.3 & 16.6 \\
\hline Serotine & $15-35$ & $58-80$ & $48-55$ & $* *$ & 49.6 & 6.0 & 20.4 \\
\hline $\begin{array}{l}\text { Whiskered/ } \\
\text { Brandt's bat }\end{array}$ & $4-9.5$ & $35-50$ & $30-39$ & $* *$ & 33.2 & 4.8 & 14.7 \\
\hline Natterer's bat & $7-12$ & $40-50$ & $36-43$ & $* *$ & 38.7 & 5.7 & 16.2 \\
\hline $\begin{array}{l}\text { Greater horseshoe } \\
\text { bat }\end{array}$ & $17-34$ & $57-71$ & $54-61$ & $* *$ & 54.2 & 3.7 & 23.4 \\
\hline $\begin{array}{l}\text { Lesser horseshoe } \\
\text { bat }\end{array}$ & $5-9$ & $35-45$ & $35-42$ & $* *$ & 36.1 & 2.8 & 16.1 \\
\hline $\begin{array}{l}\text { Based on Hutson(19 } \\
\text { ietz et al. }(2009) ; \\
\text { *_Range not current } \\
* * \text { Range often state }\end{array}$ & $\begin{array}{l}\text { 7), Gree } \\
\text { known } \\
\text { that bro }\end{array}$ & $\begin{array}{l}\text { laway an } \\
\text { due to la } \\
\text { wn long- }\end{array}$ & $\begin{array}{l}\text { Hutson } \\
\text { of data } \\
\text { red bat }\end{array}$ & 1990), S & ofield $(200$ & $\begin{array}{l}\text {, Racey } \\
\text { r than } 6\end{array}$ & $\begin{array}{l}2008) \mathrm{ar} \\
2 \mathrm{~mm}\end{array}$ \\
\hline
\end{tabular}


four limbs as other UK species do. The pipistrelle species have the third smallest thumb length which is not unexpected as they are the smallest species of bat in the UK. Long-eared bats had the longest thumb lengths with a mean value of $6.3 \mathrm{~mm}$ (SD $\pm 0.57 \mathrm{~mm}$ ). The average forearm measurements of measured specimens all fell within the range suggested for the species within the literature.

\section{Bat Claw Morphology}

\section{Claw Width}

Measurements of claw widths from the seven bat species groups studied (Fig. 3) show that serotines have, on average, the widest claws at $1.39 \mathrm{~mm}(\mathrm{SD} \pm 0.39 \mathrm{~mm})$ and that whiskered/Brandt's bats have the narrowest claws $(\mathrm{M} \pm 0.59 \mathrm{~mm}, \mathrm{SD} \pm 0.13 \mathrm{~mm})$, closely followed by lesser horseshoe bats and pipistrelle spp. Results of the Kruskal-Wallis analysis indicated that there was a significant inter-species/group difference in claw width, $(\mathrm{H}(6)=$ 155.55, $\mathrm{p}<0.0001)$. Mann Whitney post-hoc rank sums tests were conducted to determine which groups had a significant difference between their claw widths. The post-hoc rank sums tests showed that out of the 21 comparisons (made between the 7 species groups), 17 resulted in a significant difference in claw widths. The claw widths of the pipistrelle species, whiskered/Brandt's and Lesser Horseshoe Bats were not significantly different from one another. These were the three species with the smallest average claw widths. The fourth comparison that did not yield a significant difference was between the long-eared bats and the Natterer's bats, which had similar average claw widths. 


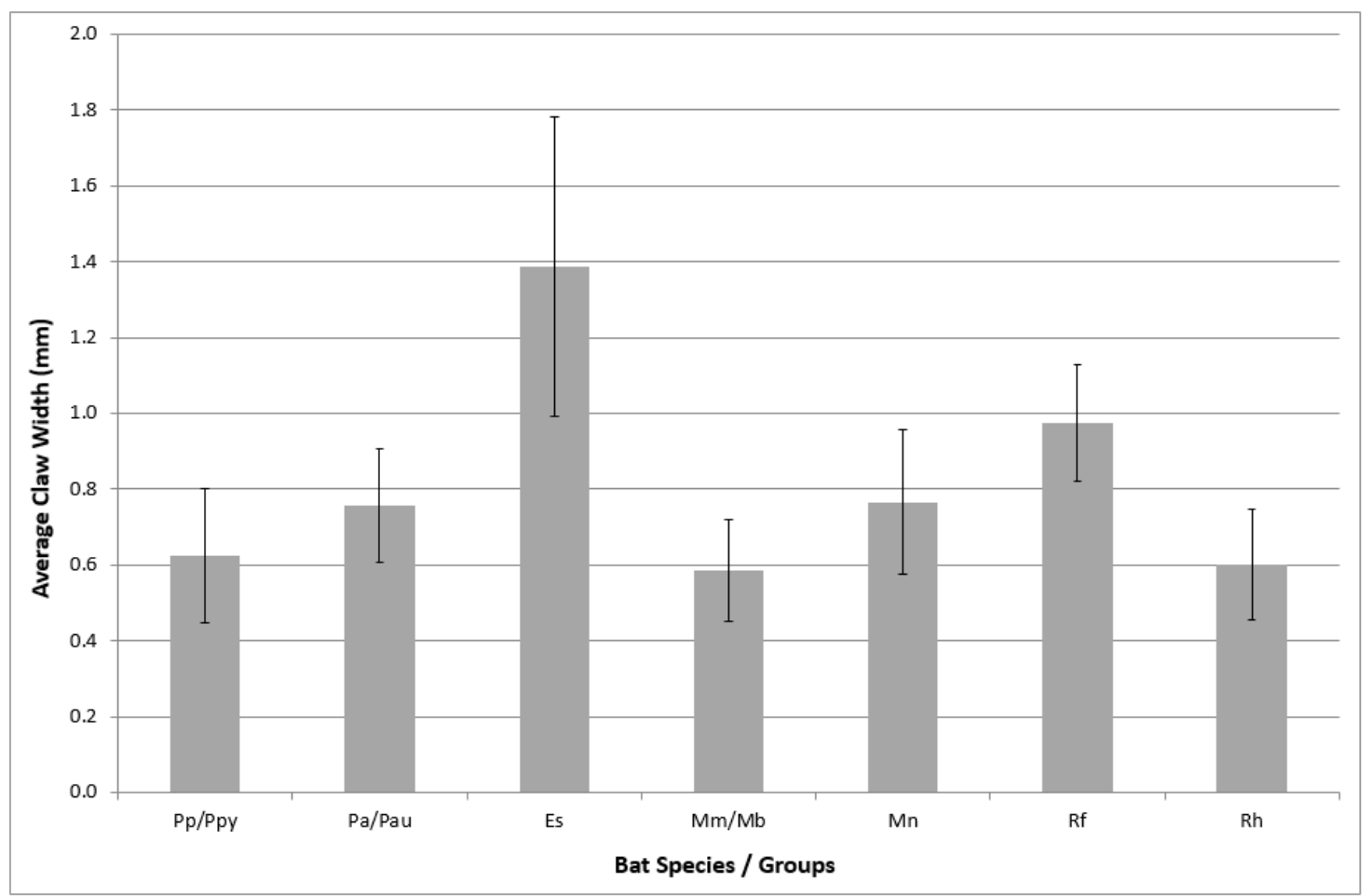

Fig.3. Average claw width data with standard deviation error bars. Abbreviations: $\mathrm{Pp} / \mathrm{Py}(P$. pipistrellus/P. pygmaeus), $\mathrm{Pa} / \mathrm{Pau}(P$. auritus/P. austriacus), Es (E. serotinus), $\mathrm{Mm} / \mathrm{Mb}$ (M. mystacinus/M. brandtii), $\mathrm{Mn}(M$. nattereri), $\mathrm{Rf}(R$. ferrumequinum), $\mathrm{Rh}$ ( $R$. hipposideros)

\section{Claw Length}

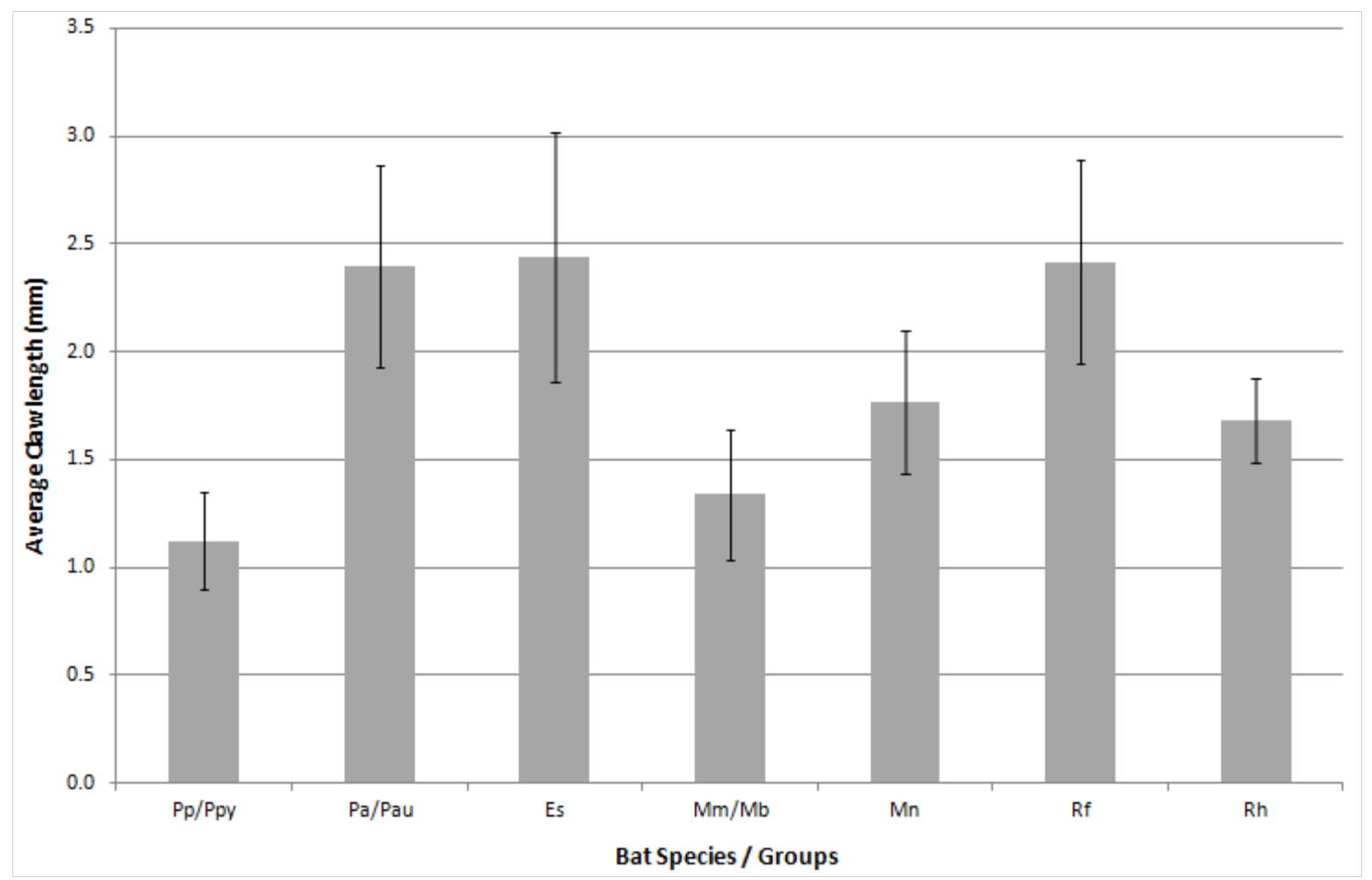

FIG 4. Average claw length data with standard deviation error bars. .

Abbreviations: $\mathrm{Pp} / \mathrm{Py}$ (P. pipistrellus/P. pygmaeus), $\mathrm{Pa} / \mathrm{Pau}(P$. auritus/ $P$. austriacus), Es (E. serotinus), $\mathrm{Mm} / \mathrm{Mb}$ ( $M$. mystacinus/M. brandti), $\mathrm{Mn}(M$. nattereri), Rf ( $R$. ferrumequinum), Rh ( $R$. hipposideros) 
The species group with the shortest average claw length $(\mathrm{M}=1.12 \mathrm{~mm}, \mathrm{SD} \pm 0.23 \mathrm{~mm})$ was pipistrelle spp. (Fig. 4).Whiskered/Brandt's bats were second shortest with a mean claw length of $1.34 \mathrm{~mm}(\mathrm{SD} \pm 0.30 \mathrm{~mm})$. Serotines had the longest claw length followed by greater horseshoe bats and long-eared bats respectively. These three groups all had a mean claw length of greater than $2.40 \mathrm{~mm}$. There was a significant, $\mathrm{H}(6)=221.05, \mathrm{p}<0.001$, difference in claw length between species/groups.

The post-hoc rank sum tests revealed that whilst there were significant differences between species groups; where the average claw lengths were similar the differences were not significant. Pipistrelle sp. were significantly $(\mathrm{p}<0.00238)$ shorter than all species groups, excluding whiskered/Brandts bats. Serotine bats were shown not to have significantly longer claws than two other species groups; long-eared bats and greater horseshoe bats. Natterer's bats and lesser horseshoe bats also did not have a significant difference between their average claw lengths.

\section{Claw Hook Ratios}

Using the Kruskal-Willis test, it was shown that bat species/group had a significant effect on the outer hook ratio of bat claws $(\mathrm{H}(6)=26.73, \mathrm{p}<0.0005)$. The outer hook ratios do not exhibit a large range between the species groups and post-hoc rank sums tests reveal that the only groups significantly different from one another are serotines and pipistrelle $\mathrm{sp} .(\mathrm{z}=-$ $3.79, \mathrm{p}<0.0005)$ and pipistrelle sp. and greater horseshoe bats $(\mathrm{z}=-3.61, \mathrm{p}<0.0005)$. There was no significant difference in outer hook ratios between the other species/groups (Fig. 5a). 


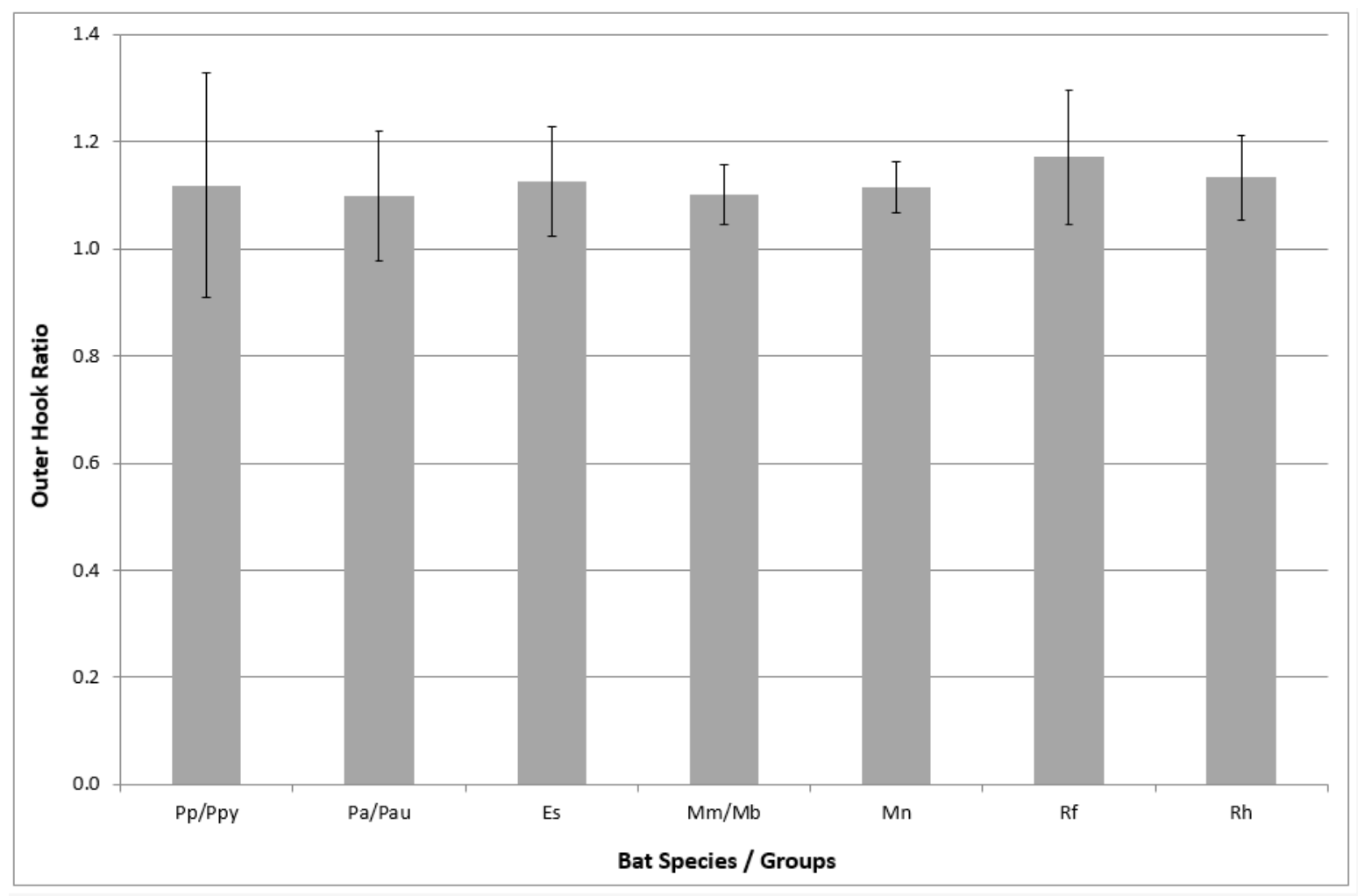

Fig. 5a. Average outer hook ratio with standard deviation error bars. . Abbreviations: Pp/Py (P. pipistrellus/P. pygmaeus), Pa/Pau (P. auritus/P. austriacus), Es (E. serotinus), $\mathrm{Mm} / \mathrm{Mb}$ ( $M$. mystacinus/M. brandtii), Mn ( $M$. nattereri), Rf ( $R$. ferrumequinum), Rh ( $R$. hipposideros)

Although the inner hook ratio results do not demonstrate large differences between the values, there is more variance than seen in the outer hook ratio results (Figs. 5b and 5a respectively). There were also significant differences in inner hook ratios between the species/groups $(\mathrm{H}(6)=30.14, \mathrm{p}<0.0001)$. As with the outer hook ratio there were significant differences between the inner hook ratio of serotines and pipistrelle $\mathrm{sp} .(\mathrm{z}=-3.33, \mathrm{p}<0.001)$ and pipistrelle sp. and greater horseshoe bats $(\mathrm{z}=-3.66, \mathrm{p}<0.0005)$. There were additional differences between pipistrelle sp. and long-eared bats $(z=-3.56, p<0.0005)$, long-eared bats and whiskered/Brandt's bats $(\mathrm{z}=-3.19, \mathrm{p}<0.001)$ and whiskered/Brandt's and greater horseshoe bats $(\mathrm{z}=--3.19, \mathrm{P}<0.001)$. These results show that whilst the uppermost surface of a bats claw shows little variation in shape between species measured, there is a greater difference between species in the curvature of the lower portion of the claw. 


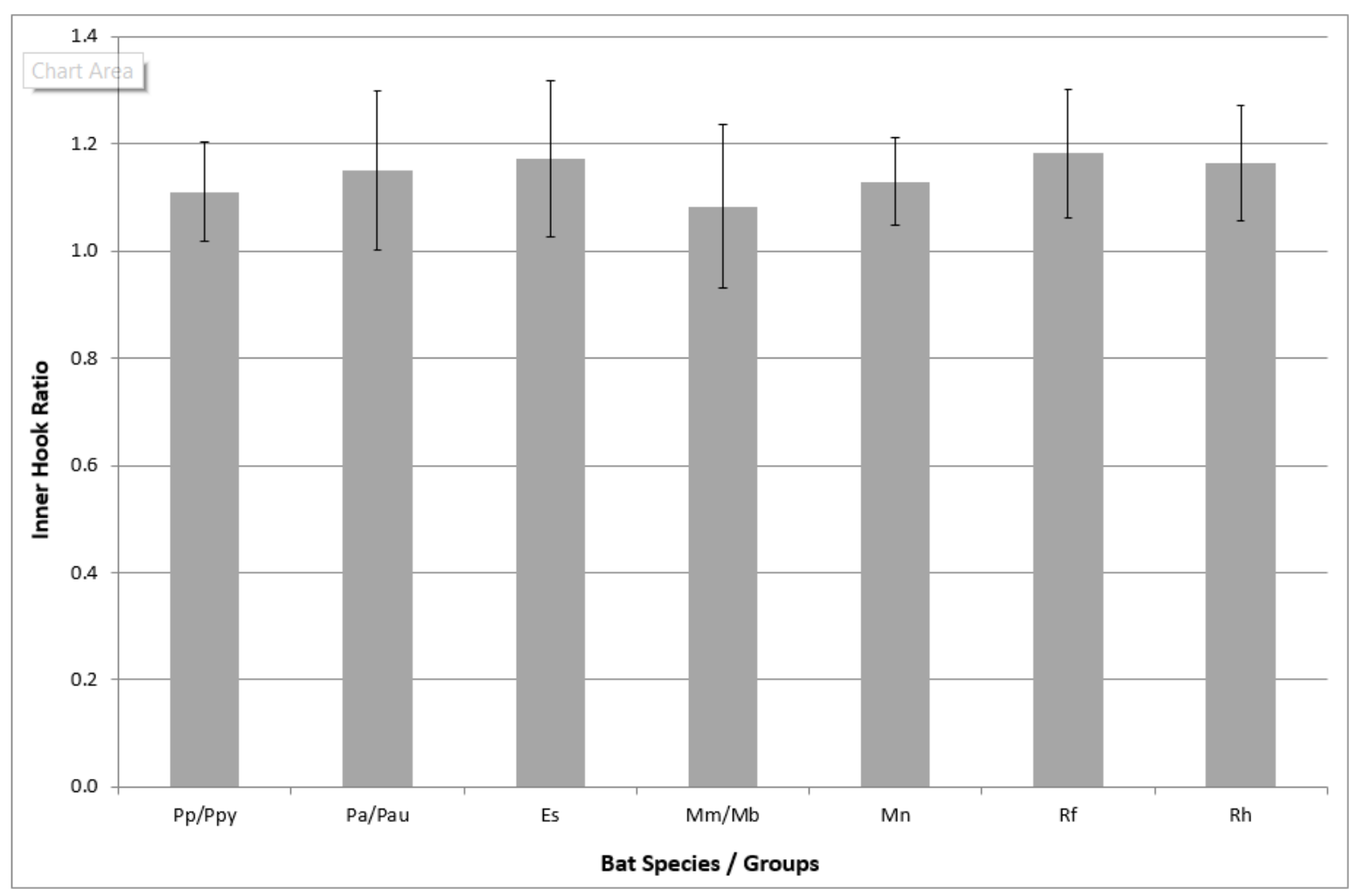

Fig.5b. Inner hook ratio with standard deviation error bars. . Abbreviations: $\mathrm{Pp} / \mathrm{Py}$ (P. pipistrellus/P. pygmaeus), Pa/Pau (P. auritus/P. austriacus), Es (E. serotinus), $\mathrm{Mm} / \mathrm{Mb}$ (M. mystacinus/M. brandtii), $\mathrm{Mn}(M$. nattereri), Rf (R. ferrumequinum), $\mathrm{Rh}$ (R. hipposideros)

\section{Bat Claw vs. Roofing Nail}

A standard roofing nail has a diameter of $2.5 \mathrm{~mm}$ (BSI, 2000), and as such this size nail is used in many standard industry tests, such as the tear test applied to roofing underlays described in BS EN 12310-1:2000. From 295 bat claws analysed, across the seven species groups analysed, the mean claw width was $0.81 \mathrm{~mm}$ ( $\mathrm{SD} \pm 0.32 \mathrm{~mm})$. This is close to a third of the standard size roofing nail, which is also straight and so has a hooked value of 0 , compared to an mean hooked ratio value of $1.12(\mathrm{SD} \pm 0.12)$.

\section{DISCUSSION}

The data collected within this research has added to the knowledge currently available for UK bat species body size and shape. It is also the first attempt to measure and analyse bat claw shape and curvature, with specific reference to those species commonly found roosting in buildings.

This information can be used in future to inform our understanding of how bats interact with the surfaces upon which they roost, in particular breathable roofing membranes. At present 
BRM strength is tested on a large scale and this may not always represent the micro-scale that needs consideration when looking at bat interactions. The results from theses bat morphometrics data reveal that bats coming into contact with BRMs in the UK vary not only in body size and shape but in their claw dimensions also. Claw width and length varies between UK species commonly found in buildings, as does the curvature of these claws. Whilst this is interesting in itself, it also demonstrates current tests on BRMs that use a standard roofing nail are not considering a fine enough scale, therefore the tests currently conducted do not represent how a bat would interact with a BRM surface. The results from the claw morphometric data are being used to develop friction and wear and tear tests on BRMs. This testing will aid understanding with regards to the potential outcomes of bat claws interacting with the surface filaments and the likely impacts and possible risks to bats roosting in roofs containing these membranes.

\section{ACKNOWLEDGEMENTS}

This research project was initiated in 2009 through a collaboration between the bat Conservation Trust and the Technologies for the Sustainable Built Environment (TSBE) centre within the University of Reading. Both of these institutions funded and supported the work throughout its development and completion. We would also acknowledge grants from the EPSRC who funded the TSBE Centre and this project and additional funding from

Natural England and Natural Resources Wales. We would also like to thank the reviewers of this paper especially Steve parker, Dr Carol Williams, Dr Dean Waters and Dr Kate Barlow who will be very sadly missed from the bat world.

\section{Literature Cited}

AlbRECT, W. 2003. Fibrous material. Pp 15-85, in: Nonwoven fabrics: Raw materials, applications, characteristics and testing processes (W. ALBRECHT, F.HILMAR \& W.KitTELmanN, eds.). Wiley-VCH, Weinheim, Germany 748p

BARLOW, K.E. \& JONES, G. 1999. Roosts, echolocation calls and wing morphology of two phonic types of Pipistrellus pipistrellus. Zeitschrift fur Saugetierkunde, 645: 257-268.

BARLOW, K.E., JONES, G. \& BARRATT, E.M. 1997. Can skull morphology be used to predict ecological relationships between bat species? A test using two cryptic species of pipistrelle. Proceedings of the Royal Society of London, 264B: 1695-1700. 
BSI. 1996. BS EN 863:1996 Protective clothing. Mechanical properties. Test method: puncture resistance. British Standards Institution, London, Pp 3-4

BSI. 2000a. BS 747:2000 Reinforced bitumen sheets for roofing. Specification, GBM48 (Construction In General). British Standards Institute, London, Pp 6-8

BSI. 2000b - BS EN 12310-1:2000 Flexible sheets for waterproofing. Determination of resistance to tearing (nail shank). Bitumen sheets for roof waterproofing, British Standards Institute, London, Pp 6-7

Dietz, C., Helversen, O. von \& Nill, D. 2009. Bats of Britain, Europe and Northwest Africa, A. \& C. Black, London 400: 81-85

Essah, E.A., SANDERS, C., BAKER, P.\& Kalagasidis, A.S. 2009. Condensation and moisture transport in cold roofs: effects of roof underlay. Build. Res. Inf. 108: 117-128.

Fowler, D.W., FreEdman, E.A. \& ScAnnella, J.B. 2009. Predatory functional morphology in raptors: interdigital variation in talon size is related to prey restraint and immobilisation technique. PloS one, 4: e7999.

JANSSENS, A. \& HENS, H. 2003. Interstitial condensation due to air leakage: a sensitivity analysis. Journal of Thermal Envelope and Building Science, 56: 115-29.

MassenauX, G. 2003. Introduction to nonwovens, Pp. 15-85 in: Albrecht, W., Fuchs, H., Kittelmann, W. (Eds.), Nonwoven Fabrics: Raw Maerials, Applications, Characteristics and Testing Processes. Wiley-VCH, Weinheim,,Germany, P748.

MorRIS, C. 2008. The 'Morris’ Batslate. The Vincent Widlife Trust, Ledbury, England, P11

NeuweILER, G. 2000. The biology of bats. Oxford University Press, Oxford, England, 324: $11-18$

RACEY, P.A. 2008. Bats. Pp 293-374 in Mammal of the British Isles Handbook. Fourth Edition. Harris, S. and Yalden, D.W. eds. The Mammal Society, Southampton, England, P799:

SCHOFIELD, H. 2008. The lesser horseshoe bat : conservation handbook, Vincent Wildlife Trust, Ledbury, England, P78 
WARING, S. D., EsSAh, E., GunNELl, K., \& BONSER, R. 2013. Double jeopardy: the potential for problems when bats interact with breathable roofing membranes in the United Kingdom. Architecture \& Environment, Pp 1-13.

WARING, S.D. 2014. The interactions between bats and breathable roofing membranes. EngD Thesis. University of Reading, UK, P376

WitteVeen, C.R. \& LuCAS, L.L. and A.A. Cooper. 2000. To tear or not to tear. Technical Report. National Roofing Contractors Association, Rosemont, Illinois. 140: 128-139

YALDEN, D.W. \& MoRris,P. 1975. The lives of bats. Quadrangle press, New York, P247 